\title{
Adhesive Strength of Gypsum Composites with Lightweight Fillers
}

\begin{abstract}
Magdaléna Doleželová ${ }^{1}$, Jitka Krejsová2, Alena Vimmrová ${ }^{3}$
${ }^{1}$ Department of Materials Engineering and Chemistry, Faculty of Civil Engineering, Czech Technical University in Prague, Thakurova 7, 16629 Prague 6 - Dejvice, Czech Republic (magdalena.dolezelova@fsv.cvut.cz) ORCID 0000-0002-0683-8723; 2Department of Materials Engineering and Chemistry, Faculty of Civil Engineering, Czech Technical University in Prague, Thakurova 7, 16629 Prague 6 - Dejvice, Czech Republic (jitka.krejsova@fsv.cvut.cz) ORCID 0000-0001-5734-7804; ${ }^{3}$ Department of Materials Engineering and Chemistry, Faculty of Civil Engineering, Czech Technical University in Prague, Thakurova 7, 16629 Prague 6 - Dejvice, Czech Republic (vimmrova@fsv.cvut.cz) ORCID 0000-0003-1148-3952
\end{abstract}

\begin{abstract}
Gypsum composites with several types of lightweight fillers were studied. Gypsum starts to be more important material nowadays, because it is one of the most environmentally friendly building binders. Therefore, there are new ways of the larger utilization of gypsum based materials to be sought. Even though the use of fillers in the gypsum is generally not necessary, because gypsum (opposite to cement or lime) does not shrink, fillers can be used for economic reasons or to improve some other properties of the gypsum material, e.g. thermal or fire resistance. We studied the adhesive strength of gypsum composites, containing three types of lightweight fillers (perlite, expanded clay aggregate and recycled PUR) and compared them with the properties of gypsum mortar with siliceous sand. It was found, that the type of the filler has principal impact on the adhesive strength of the gypsum composite.
\end{abstract}

Author Keywords. Flue Gas Desulfurization Gypsum (FDG), Expanded Clay, Expanded Perlite, Waste PUR Foam, Lightweight Fillers.

Type: Research Article

əopen Access $\square$ Peer Reviewed @(i) CC BY

\section{Introduction}

The gypsum is considered as one of the most environmentally friendly building binders nowadays. Production from secondary raw materials (FGD gypsum from flue gas desulfurization of power plants, phosphogypsum, citrogypsum from the production of citric acid), low temperature of calcination at the temperature between $100-160^{\circ} \mathrm{C}$ (for comparison: cement needs $1400^{\circ} \mathrm{C}$ ), and simple recyclability are the main reason of growing interest in searching of new ways of its utilization. Using gypsum in combination with standard fillers (quartz sand) is not so common since the gypsum does not shrink during the setting time. The use of fillers in combination with gypsum is motivated in current research primarily from the point of view of the ecology. A considerable part of recent research of gypsum with fillers is focused on recycling. The particular authors are studying mostly the possibility of waste product utilization, for example, rubber from end-of-life tires (Herrero, Mayor, and Hernández-Olivares 2013; Jiménez Rivero, Baez, and Navarro 2014) or onion skin and peanut shell (Binici and Aksogan 2017). Another alternative of filler in the gypsum is using lightweight materials with the aim of the reduction of bulk density and improve the thermal properties of gypsum composite. The polystyrene beads were used for the preparation of gypsum blocks with reduced bulk density (Sayil and Gurdal 1999). In the article by del Rio Merino et al. (2019), the authors studied the behavior of gypsum in combination with extruded (XPS) and expanded 
(EPS) polystyrene wastes. It was found that the ideal is to combine both types of polystyrene waste.

The goal of the research is to design the gypsum in the combination with lightweight fillers and to evaluate the flexural and adhesive strength of this gypsum composite. The perlite, expanded clay, and crushed recycled PUR foam are used as lightweight filler. The results obtained by measuring of mechanical properties lightweight gypsum composites are compared with gypsum composite with common quartz sand.

\section{Materials and Methods}

Four gypsum composites were prepared and tested. The commercial gypsum plaster $\left(\mathrm{CaSO}_{4} \cdot 1 / 2 \mathrm{H}_{2} \mathrm{O}\right)$ was used as a binder (produced by Saint-Gobain Construction Products $\mathrm{CZ}$, branch RIGIPS, Czech Rep.). This plaster is acquired by calcination from flue gas desulfurization product $\left(\mathrm{CaSO}_{4} .2 \mathrm{H}_{2} \mathrm{O}\right.$ ), type A2 (ČSN EN 13279-1 2014). Set retarder Retardan-200 P (produced by SIKA, Germany) was used in all composites for the better workability.

The specification and description of used fillers are given in Table 1. The maximal size of the particles was $4 \mathrm{~mm}$. The grain surface roughness of fillers was determined by the confocal laser scanning microscopy (CLSM) as the three-dimensional arithmetical mean roughness SRa [ $\mu \mathrm{m}]$ (Tasong, Lynsdale, and Cripps 1998).

\begin{tabular}{cccc}
\hline Filler & $\begin{array}{c}\text { Commercial } \\
\text { designation }\end{array}$ & Producer & $\begin{array}{c}\text { SRa of grain } \\
\text { surface [ } \boldsymbol{\mu} \text { m] }]\end{array}$ \\
\hline Standardized sand & CEN, ČSN EN 196-1 & Filtrační písky Ltd., Czech Rep. & 0.591 \\
Expanded clay & Liapor & LIAS Vintírov, Czech Rep. & 0.557 \\
Expanded perlite & EP 150 & PERLIT Ltd. Czech Rep. & 0.474 \\
Crushed PUR foam & - & DAXNER Technology, Czech Rep. & 0.351 \\
\hline
\end{tabular}

Table 1: Fillers specification

The composition of the composites was designed so that the volume of gypsum and filler was the same in all composites. The initial composition was composite with sand. The mass ratio between the gypsum and sand was determined 1:3 according to ČSN EN 196-1 (2016). The mass of lightweight fillers in other composites was calculated from its bulk density. Their values are given in Table 2.

The amount of water was determined for a flow tests diameter value of $165 \pm 5 \mathrm{~mm}$. The values are in Table 3. The amount of retarding agent was the same for each composite, $0.02 \%$ from dry gypsum weight. The initial setting time was from 13 to 45 minutes (Table 3). The composite with expanded perlite FEP has the longest setting time but the amount of water in the mixture is the lowest. This trend could be caused by the gradual release of water from the structure of expanded perlite. Probably the perlite absorbed the water very fast immediately after mixing and then the water was released gradually thereby the setting time was extended. We can say that the setting time does not depend only on the amount of water but also the type of used filler is decisive. The complete composition of gypsum composites is listed in Table 4.

\begin{tabular}{ccccc}
\hline Filler & Standard sand & Expanded clay & Expanded perlite & Crushed PUR foam \\
\hline$\left[\mathrm{kg} / \mathrm{m}^{3}\right]$ & 2575 & 1050 & 80 & 180 \\
\hline
\end{tabular}

Table 2: Bulk density of used fillers 


\begin{tabular}{cccc}
\hline $\begin{array}{c}\text { Composite } \\
\text { designation }\end{array}$ & $\begin{array}{c}\text { Flow test } \\
\text { diameter [mm] }\end{array}$ & $\begin{array}{c}\text { Initial setting } \\
\text { time [min] }\end{array}$ & $\begin{array}{c}\text { Final setting time } \\
\text { [min] }\end{array}$ \\
\hline FS & 170 & 13 & 14 \\
FEC & 165 & 15 & 17 \\
FEP & 160 & 45 & 48 \\
FPUR & 160 & 22 & 24 \\
\hline
\end{tabular}

Table 3: Properties of fresh composite

\begin{tabular}{cccccc}
\hline $\begin{array}{c}\text { Composite } \\
\text { designation }\end{array}$ & Filler [g] & & Gypsum [g] & Retardan [g] & $\begin{array}{c}\text { Water/gypsum } \\
\text { ration }\end{array}$ \\
\hline FS & standard sand & 1350.0 & 450 & 0.09 & 0.60 \\
FEC & expanded clay & 550.5 & 450 & 0.09 & 0.71 \\
FEP & expanded perlite & 41.9 & 450 & 0.09 & 0.58 \\
FPUR & crushed PUR foam & 94.4 & 450 & 0.09 & 0.89 \\
\hline
\end{tabular}

Table 4: Composition of composites

\section{Basic characterization of samples}

The specific mass was measured by helium pycnometry (Pycnomatic ATC). The bulk density was determined by the gravimetric method. The dimensions of test prisms were measured by digital caliper and the volume $V\left[\mathrm{~m}^{3}\right]$ was calculated from the dimensions. The bulk density was determined from the volume of the sample and its mass $m[\mathrm{~kg}]$ in the dry state according the equation:

$$
\rho_{V}=m / V
$$

The porosity [\%] was calculated from bulk density $\rho_{V}$ and specific mass $\rho$ according the equation:

\section{Flexural strength}

$$
p=\left(1-\rho_{V} / \rho\right) \cdot 100
$$

The three-point flexural test by mechanical press FP 100 (VEB Industriewerk Ravenstein) was used for determination of flexural strength. The set of prisms was made from each mixture. The test set included three prisms $160 \times 40 \times 40 \mathrm{~mm}$ and strength measuring was managed according to ČSN EN 13279-2 (2014). Samples were stored in laboratory for 28 days. The samples were dried at $50{ }^{\circ} \mathrm{C}$ to constant weight before testing. The measured values were evaluated by using Dean-Dixon test (Dean and Dixon 1951). The upper and lower limits of the confidence interval (Qmin, Qmax) were determined from the measured values, and they were compared with the critical value $Q$. The critical value $Q$ was determined according to the number of samples (the possible range is 3-10 samples).

\section{Adhesive strength}

Adhesive strength was determined by pull-of test using measuring device COMING plus a.s. according to ČSN EN 1015-12 (2000). The device measures the force required to pull a specified test diameter of mortar away from its substrate. The measuring assembly is shown in Figure 1. Aerated autoclaved concrete blocks were chosen as a substrate for the application of mortars. The blocks were wetted and subsequently manually coated by mortar. Then the circles with diameter $50 \mathrm{~mm}$ were cut into the fresh mortar by the special circular mold (Figure 2). 


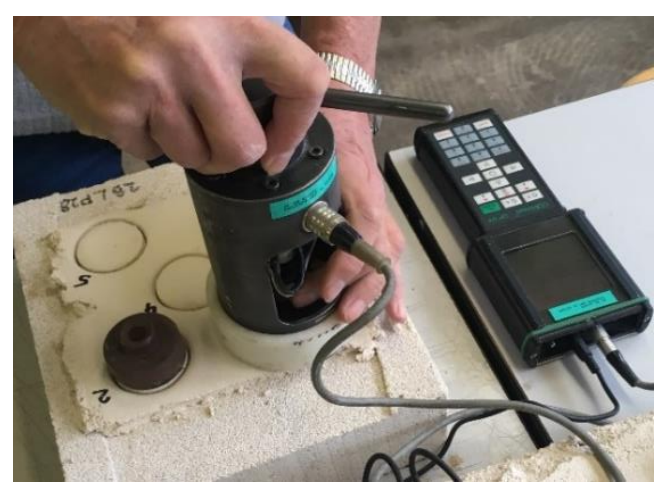

Figure 1: Measuring device COMING plus

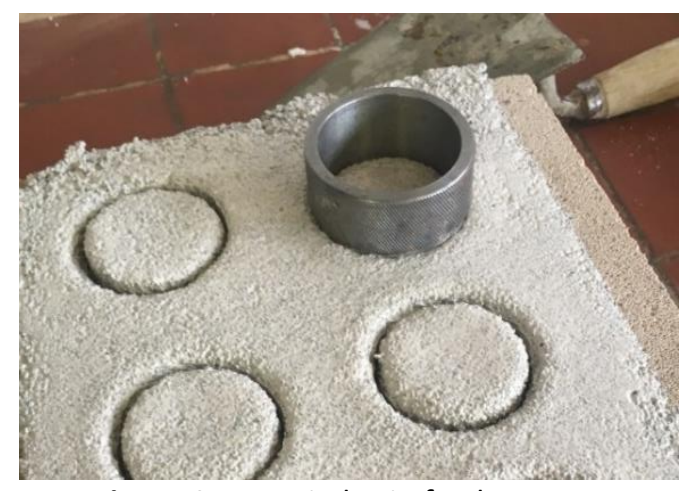

Figure 2: Test circles in fresh mortar

Stainless steel plates with pull-head were glued by two-component epoxy resin to the circular test areas 27 days after plastering. The tensile load was applied by the measuring device next day and the force at the moment of fracture $F_{u}$ was recorded. Adhesive strength $f_{u}\left[\mathrm{~N} \cdot \mathrm{mm}^{-2}\right]$ was calculated from the measured fracture force according to the equation:

$$
f_{u}=F_{u} \cdot A^{-1}
$$

where $A\left[\mathrm{~mm}^{2}\right]$ is circular test area.

The type of fracture pattern is also decisive for the evaluation of adhesive strength Figure 3. Three types of fracture patterns are distinguished and they can be combined eventually

a) cohesion fracture in the substrate

b) adhesion fracture (at the interface between mortar and substrate)

c) cohesion fracture in the mortar itself

In the case of fracture in the substrate or in the mortar may be obtained value lower than the real adhesive strength of tested mortar.

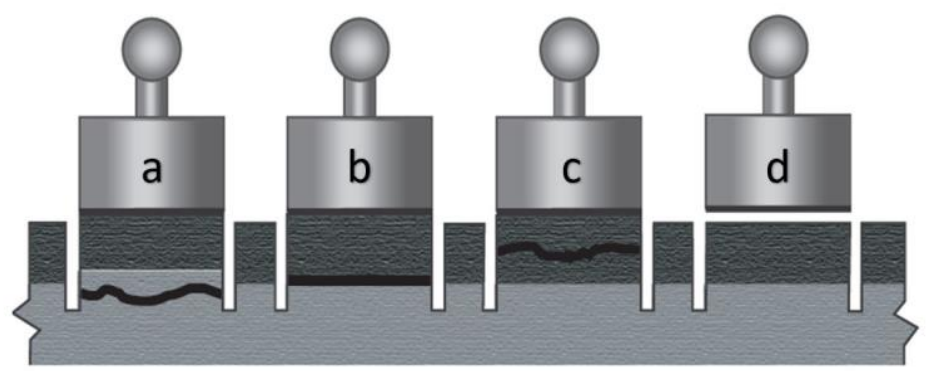

Figure 3: Type of fracture pattern: (a) cohesion fracture in the substrate, (b) adhesion fracture, (c) cohesion fracture in the mortar itself, (d) invalid result (PCTE-Industrial, n.d.) 


\section{Fracture surface roughness}

The scanning electron microscopy (device Phenom $\mathrm{XL}$ ) was used to study the fracture surface roughness of the broken samples, using 3D Roughness Reconstruction software, based on "shape from shading" technology from SEM images. The three-dimensional roughness value $S R_{f}[\mu \mathrm{m}]$ is an analogy to the arithmetical mean deviation of the profile $R a$ (two dimensional roughness) according to ISO 468 (ISO 1982).

\section{Discussion}

All measurements were carried out on the samples at the age of 28 days. The bulk density of prepared lightweight composites was minimally $42 \%$ lower than bulk density of the composite with standard sand FR $\left(1916 \mathrm{~kg} \cdot \mathrm{m}^{-3}\right)$. Therefore, also the porosity of composites with lightweight filler was higher than porosity of the composite with standard sand. The open porosity of composites was $51.5 \%, 61.3 \%$ and $59.3 \%$ for composite with expanded clay (FEC), perlite (FEP) and crushed PUR (FPUR) respectively. The open porosity of reference mixture with standard sand (FS) was $30.4 \%$.

The adhesive strength and flexural strength can be seen in Table 5. The values are given with the standard deviation. The samples with lightweight filler have a lower value of flexural strength compared to the mixture with standard sand (FS). The worst values showed the samples with crushed PUR foam. The values of fracture surface roughness are given in the same table. The values are very similar, the sample with the crushed PUR foam (FPUR) has the same roughness of fracture surface as the sample with standard sand (FS), but the value of flexural strength is three times lower. The composite with recycled PUR has worse behaviour than the samples of other composites with lightweight fillers. The lowest strength could be caused by low surface roughness of PUR particles $(0.351 \mu \mathrm{m})$ which was the lowest from all fillers. The surface of expanded clay particles and perlite particles is also smoother than grains of standard sand, which has again a negative impact on flexural strength. The filler with rough particles causes an increase of the strength of the composite.

\begin{tabular}{cccc}
\hline $\begin{array}{c}\text { Composite } \\
\text { designation }\end{array}$ & $\begin{array}{c}\text { Flexural } \\
\text { strength } \\
{[\mathrm{MPa}]}\end{array}$ & $\begin{array}{c}\text { Adhesive strength } \\
\mathrm{MPa}]\end{array}$ & $\begin{array}{c}\text { Fracture surface } \\
\text { roughness }[\boldsymbol{\mu m}]\end{array}$ \\
\hline FS & $5.89 \pm 0.19$ & $0.57 \pm 0.09$ & 1.46 \\
FEC & $4.17 \pm 0.04$ & $0.58 \pm 0.05$ & 1.72 \\
FEP & $3.85 \pm 0.17$ & $0.31 \pm 0.09$ & 1.74 \\
FPUR & $1.84 \pm 0.07$ & $0.11 \pm 0.04$ & 1.47 \\
\hline
\end{tabular}

Table 5: The values of mechanical properties

The adhesive strength was measured five times for each composite. The measuring has to be excluded in case that the fracture is between composite and the circular pull-head plates. This case did not occur during measuring these composites. The results of adhesive strength are shown in the table above. However, it is important to discuss these values with respect to the fracture pattern. In Figure 4, the composite with standard sand is shown as an example of fracture evaluation. The way of fracture of all composites is presented in the graph in Figure 5. The value of adhesive strength is not distorted if the fracture occurs at the interface between composite and substrate (i.e. type b). This type of fracture was dominant in the composite with crushed PUR foam (FPUR) which value of adhesive strength is $0.11 \mathrm{MPa}$. The composite with the perlite (FEP) was mostly fractured in the substrate (type a) itself, so adhesive strength is in fact higher than measured values. 
The adhesive strength of reference composite with standard sand (FS) could be mildly higher given the type of fracture which is mostly in the area on contact composite and substrate (type b). The fracture type of a) and c) have also occurred which suggests that the value of the adhesive strength of this composite could be mildly higher. The area of fracture in the composite with expanded clay (FEC) was almost evenly distributed between composite (type c) and substrate (type a). The real adhesive strength is, therefore, higher than the measured value.

The fracture pattern in the composite with crushed PUR foam (FPUR) is desirable for the exact determination of adhesive strength. This composite has the smoothest particles of filler and also the lowest adhesive strength. Other composites with lightweight filler (FEC, FEP) have higher measured adhesive strength and with consideration of fracture pattern, it can be supposed that the real value is higher. Based on the fracture pattern of composite with expanded perlite (FEP) (dominates type a) it can be evaluated that its adhesive strength, in reality, is also higher than the measured value. The measured values of reference composite with standard sand (FS) is very close to the real adhesive strength, because the fractures were predominantly in the interface between gypsum composites and substrate (type b).

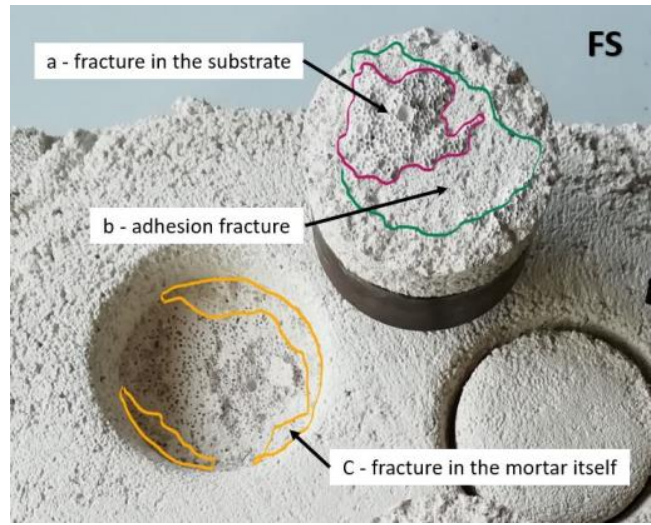

Figure 4: Fracture of the sample with standard sand

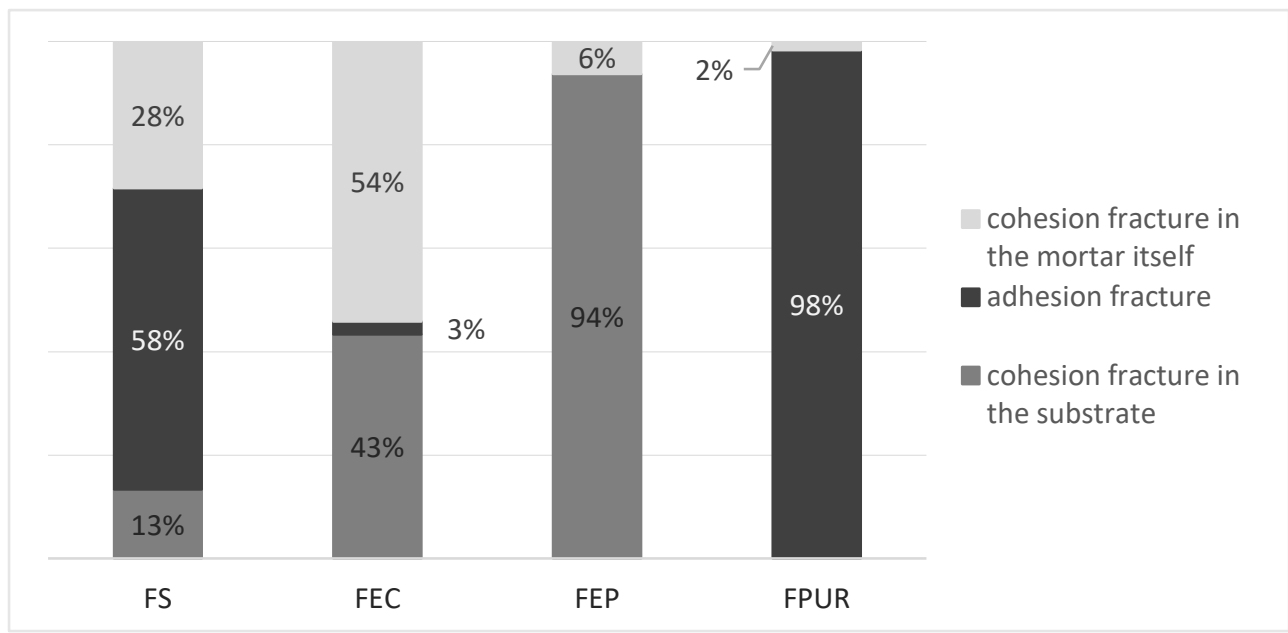

Figure 5: Type of the fracture pattern of tested composites

\section{Conclusions}

The influence of lightweight filler on properties of gypsum composite was investigated in this article. Three lightweight fillers were used in combination with gypsum and compared with the reference composite sample with standard sand filler. The workability, flexural and adhesive strength of gypsum-based composites are summarized in this article. Described tests 
are part of larger project which studies the properties and behaviour of composites with different types of fillers. The basic properties, mechanical properties, and structure of composites were described and discussed in previous articles (Doleželová, Krejsová, and Vimmrová 2019; Doleželová et al. 2020). The aim of this project is to gain the general idea and information about the behaviour of this type of gypsum composites.

The results in this article confirm that the roughness of filler grains affects the flexural strength and adhesive strength of gypsum composite. The composites with rougher filler grains have higher adhesive strength to the substrate. On the opposite side the roughness of grains does not matter in the case of fracture surface roughness. The composites (FS, FPUR) which have the same values of fracture surface roughness have totally different adhesive strengths. The difference between the values is triple. The samples with crushed PUR foam showed the worst mechanical properties (flexural strength and also adhesive strength). For other light fillers (expanded clay, expanded perlite), we can assume higher real adhesion values than which was measured (taking into account the type of fracture). This means that the real adhesive strength of these lightweight composites (FEC, FEP) can be comparable with the adhesive strength of reference composite with standard sand (FS).

\section{References}

Binici, H., and O. Aksogan. 2017. "Insulation material production from onion skin and peanut shell fibres, fly ash, pumice, perlite, barite, cement and gypsum". Materials Today Communications 10: 14-24. https://doi.org/10.1016/j.mtcomm.2016.09.004.

ČSN EN 1015-12 Methods of test for mortar for masonry-Part 12: Determination of adhesive strength of hardened rendering and plastering mortars on substrates. Test methods. 2000. Prague: Czech Standardization Institute.

ČSN EN 13279-1 Gypsum binders and gypsum plasters. Definitions and requirements. 2014. Prague: Czech Standardization Institute.

ČSN EN 13279-2 Gypsum binders and gypsum plasters. Test methods. 2014. Prague: Czech Standardization Institute.

ČSN EN 196-1 Methods of testing cement-Part 1: Determination of strength. 2016. Prague: Czech Standardization Institute.

Dean, R. B., and W. J. Dixon. 1951. "Simplified statistics for small numbers of observations". Analytical Chemistry 23, no. 4: 636-38. https://doi.org/10.1021/ac60052a025.

del Rio Merino, M., P. V. Saez, I. Longobardi, J. S. C. Astorqui, and C. Porras-Amores. 2019. "Redesigning lightweight gypsum with mixes of polystyrene waste from construction and demolition waste". Journal of Cleaner Production 220: 144-51. https://doi.org/10.1016/j.jclepro.2019.02.132.

Doleželová, M., J. Krejsová, and A. Vimmrová. 2019. "Study of the gypsum composites with several types of lightweight aggregates". In 19th International Multidisciplinary Scientific Geoconference SGEM 19: 363-69. https://doi.org/10.5593/sgem2019V/6.3/S09.047.

Doleželová, M., J. Krejsová, L. Scheinherrová, and A. Vimmrová. 2020. "Influence of fillers on structure and behaviour of gypsum mortars". IOP Conference Series: Materials Science and Engineering 800, no. 1: 012013. https://doi.org/10.1088/1757-899X/800/1/012013.

Herrero, S., P. Mayor, and F. Hernández-Olivares. 2013. "Influence of proportion and particle size gradation of rubber from end-of-life tires on mechanical, thermal and acoustic properties of plaster-rubber mortars". Materials \& Design 47: 633-42. https://doi.org/10.1016/j.matdes.2012.12.063. 
ISO. 1982. Surface roughness. Parameters, their values and general rules for specifying requirements. ISO 468. International Organization for Standardization.

Jiménez Rivero, A., A. D. Baez, and J. G. Navarro. 2014. "New composite gypsum plaster ground waste rubber coming from pipe foam insulation". Construction and Building Materials 55: 146-52. https://doi.org/10.1016/j.conbuildmat.2014.01.027.

PCTE-Industrial. n.d. "DY-2 pull off tester". Accessed January 25, 2021. https://www.industrialndt.com/dy-2-pull-off-tester.

Sayil, B., and E. Gurdal. 1999. "The physical properties of polystyrene aggregated gypsum blocks". In Durability of building materials and components, 496-504. National Research Council Canada.

Tasong, W. S., C. J. Lynsdale, and J. C. Cripps. 1998. "Aggregate-cement paste interface. II: Influence of aggregate physical properties". Cement and Concrete Research 28, no. 10: 1453-65. https://doi.org/10.1016/S0008-8846(98)00126-4.

\section{Acknowledgments}

This research was supported by the Czech Science Foundation, Project No. 19-08605S and by the project SGS19/143/OHK1/3T/11. 